\title{
Reversal of Maternal Programming of Stress Responses in Adult Offspring through Methyl Supplementation: Altering Epigenetic Marking Later in Life
}

\author{
Ian C. G. Weaver, ${ }^{1,2}$ Frances A. Champagne, ${ }^{1}$ Shelley E. Brown, ${ }^{3}$ Sergiy Dymov, ${ }^{3}$ Shakti Sharma, ${ }^{1}$ Michael J. Meaney, ${ }^{1,2}$ \\ and Moshe Szyf ${ }^{2,3}$ \\ ${ }^{1}$ Douglas Hospital Research Center, Montréal, Québec H4H 1R3, Canada, and 2McGill Program for the Study of Behaviour, Genes, and Environment and \\ ${ }^{3}$ Department of Pharmacology and Therapeutics, McGill University, Montréal, Québec H3G 1Y6, Canada
}

\begin{abstract}
Stress responses in the adult rat are programmed early in life by maternal care and associated with epigenomic marking of the hippocampal exon $1_{7}$ glucocorticoid receptor (GR) promoter. To examine whether such epigenetic programming is reversible in adult life, we centrally infused the adult offspring with the essential amino acid L-methionine, a precursor to $S$-adenosyl-methionine that serves as the donor of methyl groups for DNA methylation. Here we report that methionine infusion reverses the effect of maternal behavior on DNA methylation, nerve growth factor-inducible protein-A binding to the exon $1_{7}$ promoter, GR expression, and hypothalamic-pituitaryadrenal and behavioral responses to stress, suggesting a causal relationship among epigenomic state, GR expression, and stress responses in the adult offspring. These results demonstrate that, despite the inherent stability of the epigenomic marks established early in life through behavioral programming, they are potentially reversible in the adult brain.
\end{abstract}

Key words: maternal behavior; rat; hippocampus; glucocorticoid receptor; epigenetics; L-methionine

\section{Introduction}

The hypothalamic-pituitary-adrenal (HPA) response to stress is an inducible defense in mammals that is activated in response to threat. In primates and rodents, as in nonmammalian species, there are maternal effects on the magnitude of such defensive responses in the offspring (Higley et al., 1991; Agrawal, 2001; Meaney, 2001). In the rat, these effects are mediated by variations in maternal care such that maternal behavior stably alters the development of HPA responses to stress in the offspring through tissue-specific effects on gene expression (Liu et al., 1997; Francis et al., 1999). The magnitude of the HPA response to stress is a function of the neural stimulation of hypothalamic corticotropin-releasing factor (CRF) release, which activates the pituitary-adrenal system, as well as modulatory influences, such as glucocorticoid-negative feedback that inhibits CRF synthesis and release and, thus, dampens HPA responses to stress (De Kloet et al., 1998). As adults, the offspring of mothers that exhibit increased levels of pup licking/grooming and arched-back nursing

\footnotetext{
Received Aug. 28, 2005; revised 0ct. 12, 2005; accepted 0ct. 12, 2005.

This work was supported by a grant from the Canadian Institutes for Health Research (CIHR) (M.J.M., M.S.) and from the National Cancer Institute of Canada (M.S.). M.J.M. is supported by a CIHR Senior Scientist award, and the project was supported by a Distinguished Investigator Award (M.J.M.) from the National Alliance for Research on Schizophrenia and Affective Disorders.

Correspondence should be addressed to either of the following: Dr. Moshe Szyf, Department of Pharmacology and Therapeutics, McGill University, 3655 Drummond Street, Room 1309, Montréal, Québec, Canada H3G 1Y6, E-mail: moshe.szyf@mcgill.ca; or Dr. Michael Meaney, Department of Psychiatry, Perry Pavilion, Douglas Hospital Research Center, 6875 LaSalle Boulevard, Room E-4105.1, Verdun, Montréal, Québec, Canada H4H 1R3, E-mail: michael.meaney@mcgill.ca.

DOI:10.1523/JNEUROSCI.3652-05.2005

Copyright $\odot 2005$ Society for Neuroscience $\quad 0270-6474 / 05 / 2511045-10 \$ 15.00 / 0$
}

(high LG-ABN mothers) over the first week of life show increased hippocampal glucocorticoid receptor (GR) expression and enhanced glucocorticoid feedback sensitivity compared with adult animals reared by low LG-ABN mothers (Liu et al., 1997; Francis et al., 1999). Predictably, adult offspring of high LG-ABN mothers show decreased hypothalamic CRF expression and more modest HPA responses to stress (Liu et al., 1997). Eliminating the difference in hippocampal GR levels abolishes the effects of early experience on HPA responses to stress in adulthood (Meaney et al., 1989), suggesting that the difference in hippocampal GR expression serves as a mechanism for the effect of early experience on the development of individual differences in HPA responses to stress (Meaney, 2001).

The adult offspring of high LG-ABN mothers are also behaviorally less fearful under conditions of stress than are animals reared by low LG-ABN dams (Caldji et al., 1998). Cross-fostering studies show that, on such measures, the biological offspring of low LG-ABN mothers reared by high LG-ABN dams resemble the normal offspring of high LG-ABN (and vice versa) (Francis et al., 1999). These findings suggest that variations in maternal behavior can directly program rudimentary defensive responses to stress and serve as a mechanism for the nongenomic transmission of individual differences in stress reactivity across generations (Fleming et al., 1999; Francis et al., 1999; Meaney, 2001).

Our previous studies suggest that epigenetic mechanisms are involved in the long-term maternal programming of the offspring's responses to stress in adulthood (Weaver et al., 2004b). The exon $1_{7}$ GR promoter sequence is uniquely expressed in the brain and exhibits considerable transactivational activity (Mc- 
Cormick et al., 2000). The adult offspring of low LG-ABN mothers express significantly lower levels of the hippocampal exon $1_{7}$ mRNA transcript compared with the offspring of high LG-ABN mothers. In the adult offspring of low LG-ABN mothers, the exon $1_{7}$ GR promoter is hypermethylated, associated with hypoacetylated histone $\mathrm{H} 3$-lysine (K)-9 and reduced binding to nerve growth factor-inducible protein-A (NGFI-A) (a transcription factor also known as egr-1, krox-24, zenk, and zif-268), whereas in the adult offspring of high LG-ABN mothers, the promoter is hypomethylated, associated with hyperacetylated histone $\mathrm{H} 3-\mathrm{K} 9$ and bound to increased levels of NGFI-A (Weaver et al., 2004b). Central infusion of the histone deacetylase (HDAC) inhibitor trichostatin A (TSA) enhanced histone H3-K9 acetylation of the exon $1_{7}$ GR promoter in the offspring of the low LG-ABN mothers, increased NGFI-A binding, induced hypomethylation of CpG dinucleotide sequences in the promoter, and eliminated the maternal effect on hippocampal GR expression and HPA responses to stress (Weaver et al., 2004b). Although commonly thought that DNA methylation patterns are plastic during development and fixed in adult postmitotic tissue, these data imply that demethylation machinery is present in the adult brain and can gain access to methylated genes by pharmacologically induced alterations in chromatin conformation. If indeed the epigenetic status of the adult genome is truly in a dynamic equilibrium of methylation verses demethylation, it should be possible to reverse the DNA methylation pattern in the other direction by inducing hypermethylation.

Dietary methionine is converted by methionine adenosyltransferase into $S$-adenosyl-methionine (also termed SAM) (Mudd and Cantoni, 1958; Cantoni, 1975), which serves as the donor of methyl groups for DNA methylation. The methyldonor SAM has been proposed to cause DNA hypermethylation by either activating DNA methylation enzymes or inhibiting active demethylation (Detich et al., 2003). Importantly, the synthesis of SAM is dependent on the local availability of methionine (Cooney, 1993). We reasoned that, if the DNA methylation pattern of the exon $1_{7}$ GR promoter within the adult offspring remains sensitive to both DNA methylation and DNA demethylation enzymes, then increasing brain methionine levels should result in DNA hypermethylation and a reversal of the maternal programming of GR expression and HPA responses to stress. Our current findings support this hypothesis and suggest that the methylation status of specific DNA sequences is modifiable even in postmitotic cells, and, thus, the otherwise stable effects of maternal care on phenotype are potentially reversible.

\section{Materials and Methods}

Animals and maternal behavior. The animals used in all studies were derived from Long-Evans hooded rats born in our colony from animals originally obtained from Charles River Canada (St. Catharine's, Québec, Canada). The animals were mated with males drawn randomly from a breeding stock maintained in our colony. In cases in which the offspring of high or low LG-ABN mothers were used in studies, no more than two animals per group were drawn from any single mother. At the time of weaning on day 22 of life, pups were housed in same-sex, same-litter groups of three to four animals per cage until day 45 of life and two animals per cage from this point until the time of testing, which occurred no earlier than $100 \mathrm{~d}$ of age. All procedures were performed according to guidelines developed by the Canadian Council on Animal Care and protocol approved by the McGill University Animal Care Committee. Behavioral observations were performed with mothers and their litters housed in $46 \times 18 \times 30 \mathrm{~cm}$ Plexiglas cages that permitted a clear view of all activity within the cage. Food and water were provided ad libitum. The colony was maintained on a $12 \mathrm{hr}$ light/dark schedule with lights on at
8:00 A.M. Maternal behavior was scored as described previously (Myers et al., 1989; Champagne et al., 2003). The behavior of each dam was observed for six 100 min observation periods daily for the first $10 \mathrm{~d}$ postpartum. Observations occurred at regular times each day, with four periods during the light phase (9:00 A.M., 12:00 P.M., 3:00 P.M., and 6:00 P.M.) and two periods during the dark phase of the light/dark cycle (6:00 A.M. and 9:00 P.M.). Within each observation period, the behavior of each mother was scored every $4 \mathrm{~min}$ ( 25 observations per period for six periods per day, for 150 observations per mother per day). All observations were performed by individuals unaware of the origin of the animals. On occasion, because of disturbances in the animal room, observation sessions were uncompleted. Although all mothers were observed for exactly the same number of periods, there was some variation across days. The data were therefore analyzed as the percentage of observations in which animals engaged in the target behavior. The following behaviors were scored: mother off pups; mother licking/grooming any pup; and mother nursing pups in an arched-back posture, a "blanket" posture in which the mother lays over the pups, or a passive posture in which the mother is lying either on her back or side while the pups nurse (Myers et al., 1989). Note that behavioral categories are not mutually exclusive. For, example, licking/grooming most often occurred while the mother was nursing the pups. The frequency of maternal licking/grooming and arched-back nursing across a large number of mothers is normally and not bimodally distributed (Champagne et al., 2003). Hence, the high and low LG-ABN mothers represent two ends of a continuum rather than two distinct populations. To define these populations for the current study, we observed the maternal behavior in a cohort of 32 mothers and devised the group mean and SD for each behavior over the first $10 \mathrm{~d}$ of life. High LG-ABN mothers were defined as females whose frequency scores for both licking/grooming and arched-back nursing were $>1 \mathrm{SD}$ above the mean. Low LG-ABN mothers were defined as females whose frequency scores for both licking/grooming and arched-back nursing were $>1$ SD below the mean. Previous reports (Levine, 1994; Meaney, 2001) of licking/grooming behavior suggest that the frequency of licking/ grooming and arched-back nursing are highly correlated $(r>+0.90)$.

Intracerebroventricular infusions. For intracerebroventricular cannula placement, 90-d-old (adult) male high and low LG-ABN offspring were anesthetized, and the area between the ears (across the neck and scapulae) was shaven. The shaven skin was swabbed with iodine, and the animal was mounted and secured in a stereotaxic frame. A cut was made directly down the midline, and the fascia and muscle were separated to expose the skull surface, which was cleaned and dried with sterile gauze and cotton swabs. A stainless-steel guide cannula (22 gauge), $8 \mathrm{~mm}$ length (Plastics One, Roanoke, VA) was aimed at the left lateral ventricle (1.5 $\mathrm{mm}$ posterior to bregma, $2.0 \mathrm{~mm}$ lateral to midline, and $3.0 \mathrm{~mm}$ ventral to the brain surface). Guide cannulas were secured with dental cement and three stainless-steel jeweler's screws and kept patent with stainless-steel stylets (30 gauge). The animals were placed under heat lamps until they regained consciousness, and then they were transferred to single cages. After a $7 \mathrm{~d}$ recovery period, animals received a single infusion every day for 7 consecutive days as described below. Animals were removed from their cages and gently held while an infusion cannula (28 gauge) attached to tubing (polyethylene 20) was lowered into the guide. A total volume of $2 \mu \mathrm{l}$ of TSA ( $100 \mathrm{ng} / \mathrm{ml}$ in saline), L-methionine (100 $\mu \mathrm{g} / \mathrm{ml}$ in saline), or saline vehicle alone was injected (using a Hamilton $10 \mu \mathrm{l}$ microsyringe) through the infusion cannula over a $1 \mathrm{~min}$ period. Infusion cannulas were left in place for an additional $1 \mathrm{~min}$ after infusion. Animals were then returned to their home cage.

Sodium bisulfite mapping. Sodium bisulfite mapping was performed using the procedure (Frommer et al., 1992) in which sodium bisulfite solution (3.6 M NaBis/1 mM hydroquinone) was added to the resuspended DNA and incubated $\left(14 \mathrm{~h}, 55^{\circ} \mathrm{C}\right)$. DNA was eluted (QIAquick, PCR purification kit; Qiagen, Hilden, Germany) in Tris buffer (10 mM), $\mathrm{pH} 8.5$, and $\mathrm{NaOH}(3 \mathrm{M})$ was added to a final concentration of $0.3 \mathrm{~N}$ $\mathrm{NaOH}$ and incubated $\left(15 \mathrm{~min}, 37^{\circ} \mathrm{C}\right) . \mathrm{NH}_{4} \mathrm{OAc}(10 \mathrm{M})$ was added to a final concentration of $3 \mathrm{M} \mathrm{NH}_{4} \mathrm{OA}$, followed by the addition of tRNA ( 0.1 $\mathrm{mg} / \mathrm{ml}$ ) and $\mathrm{EtOH}(2 \mathrm{v} / \mathrm{v}, 95 \%)$, and the bisulfited DNA solution was cooled $\left(20 \mathrm{~min},-20^{\circ} \mathrm{C}\right)$. The precipitated solution was then centrifuged $\left(4^{\circ} \mathrm{C}, 13,200 \mathrm{rpm}, 30 \mathrm{~min}\right)$, and the pelleted DNA was lyophilized and 
resuspended in $\mathrm{ddH}_{2} \mathrm{O}(50 \mathrm{ng} / \mathrm{ml})$. The rat exon $1_{7} \mathrm{GR}$ promoter region (GenBank accession number AJ271870) of the sodium bisulfite-treated hippocampal DNA (50 ng/ml) was subjected to PCR amplification using outside primers (forward, 1646-TTTTTTAGGTTTTTTTAGAGGG1667; reverse, 1930-ATTTCTTTAATTTCTCTTCTCC-1908). The thermocycler protocol involved an initial denaturation cycle $\left(5 \mathrm{~min}, 95^{\circ} \mathrm{C}\right)$, 34 cycles of denaturation $\left(1 \mathrm{~min}, 95^{\circ} \mathrm{C}\right)$, annealing $\left(2 \min 30 \mathrm{~s}, 56^{\circ} \mathrm{C}\right)$ and extension $\left(1 \mathrm{~min}, 72^{\circ} \mathrm{C}\right)$, followed by a final extension cycle $(5 \mathrm{~min}$, $\left.72^{\circ} \mathrm{C}\right)$, terminating at $4^{\circ} \mathrm{C}$. The PCR product $(285 \mathrm{bp})$ was used as a template for subsequent PCR reactions using nested primers (forward, 1738-TTTTTTTGTTAGTGTGATATATTT-1761; reverse, 1914-TTCT CCCAAACTCCCTCC-1897). The nested PCR product (177 bp) was purified (QIAquick, PCR purification kit; Qiagen), and the DNA was eluted in Tris buffer ( $10 \mathrm{~mm}), \mathrm{pH}$ 8.5. The purified product was separated on an agarose gel (2\%). The band corresponding to DNA fragment (177 bp) was cut from the gel, and DNA was extracted (QIAEX, II Agarose Gel Extraction; Qiagen) and then eluted in Tris buffer (10 mM), $\mathrm{pH}$ 8.5. The PCR product (177 bp) was then subcloned (Original TA cloning kit; Invitrogen, Carlsbad, CA), transformed into chemically made competent bacteria, and grown on 5-bromo-4-chloro-3-indolyl- $\beta$-D-galactopyranoside $(40 \mathrm{mg} / \mathrm{ml})$-treated ampicillin $(100 \mathrm{mg} / \mathrm{ml}$; Invitrogen, Carlsbad, CA) plates $\left(16 \mathrm{~h}, 37^{\circ} \mathrm{C}\right)$. Ten different clones per plate were mini prepped and grown $\left(14 \mathrm{~h}, 37^{\circ} \mathrm{C}\right)$ in $2 \mathrm{ml}$ of Lauria broth treated with ampicillin $(100 \mathrm{mg} / \mathrm{ml})$, and the pellet was resuspended in STET (sucrose, Triton X-100, $0.5 \mathrm{~m}$ EDTA, and $1 \mathrm{~m}$ Tris, pH 8.0). Lysozyme (10 $\mathrm{mg} / \mathrm{ml}$; Roche Diagnostics, Mannheim, Germany) dissolved in Tris buffer $(25 \mathrm{~mm}), \mathrm{pH} 8.0$, was added to each sample $\left(3 \mathrm{~s}, 22^{\circ} \mathrm{C}\right)$, which was subsequently boiled $\left(45 \mathrm{~s}, 100^{\circ} \mathrm{C}\right)$. Finally, the recovered DNA was resuspended in $1 \times$ Tris (10 mm; pH 8)-EDTA (1 mm) TE/RNase A (10 mg/ $\mathrm{ml}$ ). Ten plasmids, containing the ligated exon $1_{7}$ GR promoter DNA fragment, were sequenced per animal (T7 sequencing kit, United States Biochemical; Amersham Biosciences), starting from procedure $\mathrm{C}$ in the protocol by the manufacturer. The sequencing reactions were resolved on a denaturing PAGE $(6 \%)$ run in $1 \times$ Tris-borate-EDTA $(3 \mathrm{~h}, 75 \mathrm{~W}$, $22^{\circ} \mathrm{C}$ ) and visualized by autoradiography.

5-Methylcytosine and neuronal-specific nuclear protein immunohistochemistry. Whole brains were removed from 90 -d-old (adult) male offspring by rapid decapitation $<1 \mathrm{~min}$ after their removal from the home cage. Coronal sections $(16 \mu \mathrm{n})$ corresponding to stereotaxic levels from -2.30 to $-3.80 \mathrm{~mm}$ from bregma were thaw mounted (three sections per slide) onto gelatin-subbed slides and temporarily stored within the cryostat $\left(-20^{\circ} \mathrm{C}\right)$. Once sectioning was complete, the slides were vacuum dried within a desacator $\left(4^{\circ} \mathrm{C}, 14 \mathrm{~h}\right)$ and stored at $-80^{\circ} \mathrm{C}$. All sections were processed in parallel. Sections were fixed $\left(10 \mathrm{~min}, 22^{\circ} \mathrm{C}\right)$ in paraformaldehyde (4\%), washed with $50 \%$ ethanol (30 min), blocked in $10 \%$ FCS plus PBS containing $0.2 \%$ Triton X-100 ( $2 \mathrm{~h})$, and immersed in $2 \mathrm{~N}$ $\mathrm{HCl}\left(2 \mathrm{~h}, 37^{\circ} \mathrm{C}\right)$. Anti-5-methylcytosine (5-mC) antibody (a kind gift from Dr. Alain Niveleau, Université Joseph Fourier, Grenoble, France) diluted 1:500 in 5\% serum plus PBS and mouse anti-neuronal-specific nuclear protein (NeuN) Alexa-Fluor 488-conjugated monoclonal antibody (Chemicon, Temecula, CA) diluted 1:1000 in 5\% serum plus PBS were applied to each section, which were then incubated $\left(1 \mathrm{~h}, 37^{\circ} \mathrm{C}\right)$ and left to hybridize $\left(40 \mathrm{~h}, 4^{\circ} \mathrm{C}\right)$. Negative control sections for each rat were produced by omitting the addition of the primary antibodies. Rabbit anti-mouse IgG Alexa-Fluor 568 (Invitrogen, Carlsbad, CA) diluted 1:600 in 5\% serum plus PBS was applied to the 5-mC-labeled sections. The sections were then dried $(2 \mathrm{~h})$ and coverslipped with Aqua Polymount (Polysciences, Warrington, PA). Visualization of 5-mC and NeuN labeling was performed using a Zeiss (Oberkochen, Germany) Axioplan 2 Imaging fluorescence microscope, equipped with a highresolution color digital camera and connected to a computer running Zeiss Axiovision 4.1 Software. The appropriate filter combination and a 63 plan-apochromatic oil-immersion objective was used to capture images of the 5-mC-positive nuclei over the entire area of the dentate gyrus and CA1, CA2, and CA3 hippocampal regions of Ammon's horn. These images were converted to Tiff format and imported into an MCID Elite image analysis system (Imaging Research, St. Catharines, Ontario, Canada) for quantification. An observer blind to the experimental conditions performed the analysis.
Chromatin immunoprecipitation assay. In the preparation of fixed tissue, 90-d-old (adult) male high and low LG-ABN offspring were deeply anesthetized with sodium pentobarbital $(60 \mathrm{mg} / \mathrm{kg}$, i.p.) and then transcardially perfused with heparinized saline flush $(30-60 \mathrm{ml})$, followed by paraformaldehyde (4\%) in PBS, pH 7.4, for 15 min. After perfusion, all brains were removed and postfixed in the same fixation solution overnight at $4^{\circ} \mathrm{C}$ and then transferred to phosphate buffer sucrose (20\%) for $48 \mathrm{~h}$. Chromatin immunoprecipitation (ChIP) assays (Crane-Robinson et al., 1999) were performed following the ChIP assay kit protocol (Upstate Biotechnology, Lake Placid, NY). Hippocampi were dissected from each rat brain, and chromatin was immunoprecipitated using rabbit polyclonal anti-acetyl-histone H3 antibody (Upstate Cell Signaling Solutions, Waltham, MA), rabbit polyclonal anti-NGFI-A antibody (Santa Cruz Biotechnology, Santa Cruz, CA), or normal rabbit IgG nonimmune antibody (Santa Cruz Biotechnology). One-tenth of the lysate was kept to quantify the amount of DNA present in different samples before immunoprecipitation (input). Protein-DNA complexes were uncross-linked by adding $20 \mu \mathrm{l}$ of $\mathrm{NaCl}(5 \mathrm{M})$ to each sample $\left(4 \mathrm{~h}, 65^{\circ} \mathrm{C}\right)$, followed by 10 $\mu \mathrm{l}$ of EDTA $(0.5 \mathrm{M}), 20 \mu \mathrm{l}$ of Tris- $\mathrm{HCl}(1 \mathrm{M}), \mathrm{pH} 6.5$, and $2 \mu \mathrm{l}$ of Proteinase $\mathrm{K}\left(10 \mathrm{mg} / \mathrm{ml} ; 1 \mathrm{~h}, 45^{\circ} \mathrm{C}\right)$. After phenol-chloroform $(0.5 \mathrm{v} / \mathrm{v})$ extraction, the free-DNA was ethanol $(2 \mathrm{v} / \mathrm{v}, 95 \%)$ precipitated with $5 \mu \mathrm{l}$ of tRNA $(10 \mathrm{mg} / \mathrm{ml})$ and resuspended in $100 \mu \mathrm{l}$ of $1 \times$ TE. The rat hippocampal exon $1_{7}$ GR promoter region (GenBank accession number AJ271870) of the uncross-linked DNA was subjected to PCR amplification (forward primer, 1750-TGTGACACACTTCGCGCA-1767; reverse primer, 1943-GGAGGGAAACCGAGTTTC-1926). PCR reactions were performed after the FailSafe PCR system protocol using FailSafe PCR 2X PreMix D (EPICENTRE, Madison, WI). The thermocycler protocol in volved an initial denaturation cycle $\left(5 \mathrm{~min}, 95^{\circ} \mathrm{C}\right), 34$ cycles of denaturation $\left(1 \mathrm{~min}, 95^{\circ} \mathrm{C}\right)$, annealing $\left(1 \mathrm{~min}, 56^{\circ} \mathrm{C}\right)$, and extension $(1 \mathrm{~min}$, $72^{\circ} \mathrm{C}$ ), followed by a final extension cycle $\left(10 \mathrm{~min}, 72^{\circ} \mathrm{C}\right)$ terminating at $4^{\circ} \mathrm{C}$. To control for unequal loading of acetyl-histone H3-K9 immunoprecipitate, the rat hippocampal $\beta$-actin promoter- $\alpha$ region (GenBank accession number V01217) of the uncross-linked DNA was subjected to PCR amplification (forward primer, 10-TCAACTCACTTCTCTCTACT-29; reverse primer, 161-GCAAGGCTTTAACGGAAAAT-180). PCR reactions were performed after the FailSafe PCR system protocol using FailSafe PCR 2X PreMix L (EPICENTRE) with the same thermocycler protocol as described previously. To control for purity of the NGFI-A immunoprecipitate, the rat hippocampal exon $1 \mathrm{~b}$ estrogen receptor (ER)- $\alpha$ promoter region (GenBank accession number X98236) of the uncross-linked DNA was subjected to PCR amplification (forward primer, 1836-GAAGAAACTCCCCTCAGCAT-1855; reverse primer, 2346-GAAATCAAAACACCGATCCT-2327). PCR reactions were performed following the FailSafe PCR system protocol using FailSafe PCR 2X PreMix A (EPICENTRE). The thermocycler protocol involved an initial denaturation cycle $\left(5 \mathrm{~min}, 95^{\circ} \mathrm{C}\right), 34$ cycles of denaturation $(1 \mathrm{~min}$, $\left.95^{\circ} \mathrm{C}\right)$, annealing $\left(1 \mathrm{~min}, 60^{\circ} \mathrm{C}\right)$, and extension $\left(1 \mathrm{~min}, 72^{\circ} \mathrm{C}\right)$, followed by a final extension cycle $\left(10 \mathrm{~min}, 72^{\circ} \mathrm{C}\right)$ terminating at $4^{\circ} \mathrm{C}$. PCR reactions on DNA purified from non-immunoprecipitated samples and immunoprecipitated samples were repeated exhaustively using varying amounts of template to ensure that results were within the linear range of the PCR. A total of $10 \mu \mathrm{l}$ of the amplified products were separated on an agarose gel $(2 \%)$ and post-stained with ethidium bromide to visualize bands corresponding to the exon $1_{7}$ glucocorticoid receptor promoter (194 bp), $\beta$-actin promoter- $\alpha$ (171 bp), or exon 1b ER- $\alpha$ promoter (493 bp) DNA fragments. Nucleic acids were transferred by Southern blot $\left(14 \mathrm{~h}, 22^{\circ} \mathrm{C}\right)$ to positively charged nylon transfer membrane (Hybond- $\mathrm{N}^{+}$; Amersham Biosciences). An oligonucleotide $\left(20 \mathrm{bp}\right.$ ) specific for the exon $1_{7}$ GR promoter sequence (GenBank accession number AJ271870) was synthesized (forward, 1881-TCCCGAGCGGTTCCAAGCCT-1907), as well as an oligonucleotide (21 bp) specific for the $\beta$-actin promoter- $\alpha$ sequence (GenBank accession number V01217; forward: 95-GTAAA AAAATGCTGCACTGTC-115) and an oligonucleotide (20 bp) specific for the exon $1 \mathrm{~b}$ ER- $\alpha$ promoter sequence (GenBank accession number X98236; forward: 1942-AGAAAGCACTGGACATTTCT-1961). The oligonucleotides were radiolabeled [ $1 \mu \mathrm{l}$ of $\mathrm{T} 4$ polynucleotide kinase (PNK); Promega, Madison, WI] with $5 \mu$ of $\left[\gamma^{-32}\right.$ P $]$ ATP (Amersham Biosciences) $\left(2 \mathrm{~h}, 37^{\circ} \mathrm{C}\right)$ and then hybridized to the membranes, which 
were exposed to PhosphorImager screens (Type BAS-III Imaging Plate; Fujifilm, Tokyo, Japan) overnight at $22^{\circ} \mathrm{C}$. The screens were scanned by PhosphorImager (Storm840; Molecular Dynamics, Sunnyvale, CA) running Storm840 software (Molecular Dynamics). Relative optical density (ROD) readings were determined using a computer-assisted densitometry program (ImageQuant; Molecular Dynamics). To calculate the final signal for each sample, the ROD value of the band within the antibody lane was divided by the ROD value of the band within the input lane. To control for equal loading between samples, the final signal of the exon $1_{7}$ GR promoter, amplified from the acetyl-histone $\mathrm{H} 3-\mathrm{K} 9$ immunoprecipitations, was divided by the final signal from the $\beta$-actin promoter- $\alpha$ amplified from the same precipitate.

RT-PCR analysis. Whole brains were removed by rapid decapitation $<1$ min after the animal's removal from the home cage. The hippocampal tissue was dissected, snap frozen on dry ice, and stored at $-80^{\circ} \mathrm{C}$. Total hippocampal RNA was isolated with the Trizol reagent method (Invitrogen, Burlington, Ontario, Canada), and the precipitated RNA was dissolved in RNase-free $\mathrm{H}_{2} \mathrm{O}$ and quantified $(\sim 1.0 \mathrm{mg} / \mathrm{ml})$ by UV photospectrometry with absorbance at $260 \mathrm{~nm}$. The overall quality and yield of the RNA preparation was determined by denaturing agarose (1\%) gel electrophoresis fractionation. In addition, RNA integrity was confirmed using an Agilent Bioanalyzer (Agilent Technologies, Palo Alto, CA). cDNA was synthesized in a $20 \mu \mathrm{l}$ reaction volume containing $2 \mu \mathrm{g}$ of total RNA, $40 \mathrm{U}$ of Moloney murine leukemia virus reverse transcriptase (MBI Fermentas Life Sciences, Burlington, Ontario, Canada), $5 \mu \mathrm{M}$ random primer (Roche Diagnostics), a $1 \mathrm{~mm}$ concentration of each of the four deoxynucleotide triphosphates, and $40 \mathrm{U}$ of RNase inhibitor (Roche Diagnostics). The mRNA was denatured $\left(5 \mathrm{~min}, 70^{\circ} \mathrm{C}\right)$, the random primers were annealed $\left(10 \mathrm{~min}, 25^{\circ} \mathrm{C}\right)$, and mRNA was reverse transcribed $\left(1 \mathrm{~h}, 37^{\circ} \mathrm{C}\right)$. The reverse transcriptase was heat inactivated $\left(10 \mathrm{~min}, 72^{\circ} \mathrm{C}\right)$, and the products were stored at $-20^{\circ} \mathrm{C}$. The rat hippocampal GR exon $1_{7}$ region (GenBank accession number AJ271870) was subjected to PCR amplification (forward primer, 5' -TCCCAGGC CAGTTAATATTTGC-3'; reverse primer, 5'-TTGAACTCTTGGGG TTCTCTGG-3'). To control for equal loading, the rat hippocampal $\beta$-actin exon region (GenBank accession number V01217) was also subjected to PCR amplification (forward primer, 5'-GTTGCTAGCCAG GCTGTGCT-3'; reverse primer, 5'-CGGATGTCCACGTCACACTT$\left.3^{\prime}\right)$. The GR exon $1_{7}$ and $\beta$-actin amplification were performed in parallel, using a $25 \mu \mathrm{l}$ reaction mixture containing $1.5 \mu \mathrm{l}$ of synthesized cDNA product, $2.5 \mu \mathrm{l}$ of $10 \times$ PCR buffer, $1.5 \mathrm{~mm} \mathrm{MgCl}_{2}, 0.2 \mathrm{~mm}$ dNTPs, $1 \mathrm{U}$ of Taq polymerase (all from MBI Fermentas Life Sciences), and 0.5 $\mu \mathrm{M}$ of each primer. The thermocycler protocol involved an initial denaturation cycle $\left(5 \mathrm{~min}, 95^{\circ} \mathrm{C}\right), 20-30$ cycles of denaturation $\left(30 \mathrm{~s}, 95^{\circ} \mathrm{C}\right)$, annealing $\left(30 \mathrm{~s}, 60^{\circ} \mathrm{C}\right)$, and extension $\left(30 \mathrm{~s}, 72^{\circ} \mathrm{C}\right)$, followed by a final extension cycle $\left(5 \mathrm{~min}, 72^{\circ} \mathrm{C}\right)$ terminating at $4^{\circ} \mathrm{C}$. Samples were removed every two cycles between 20 and 30 cycles to determine the linear range of the PCR amplification. Products were separated on an agarose gel (2\%) to visualize bands corresponding to the GR exon $1_{7}(514 \mathrm{bp})$ or $\beta$-actin (470 bp) cDNA fragments. Nucleic acids were transferred by Southern blot $\left(14 \mathrm{~h}, 22^{\circ} \mathrm{C}\right)$ to positively charged nylon transfer membrane (Hybond- $\mathrm{N}^{+}$; Amersham Biosciences). An oligonucleotide (20 bp) specific for the GR exon $1_{7}$ sequence (GenBank accession number AJ271870; forward, 5' -TCCCAGGCCAGTTAATATTTGC-3') was synthesized, as well as an oligonucleotide (21 bp) specific for the $\beta$-actin sequence (GenBank accession number V01217; forward, 5'-GTTGCTAGCCAGGC TGTGCT-3'). The oligonucleotides were radiolabeled ( $1 \mu \mathrm{l}$ of T4 PNK; Promega) with $5 \mu$ l of $\left[\gamma^{-32} \mathrm{P}\right]$ ATP (Amersham Biosciences) $\left(2 \mathrm{~h}, 37^{\circ} \mathrm{C}\right)$ and then hybridized to the membranes, which were exposed to PhosphorImager screens (Type BAS-III Imaging Plate; Fujifilm) overnight at $22^{\circ} \mathrm{C}$. The screens were scanned by PhosphorImager (Storm840; Molecular Dynamics) running Storm840 software (Molecular Dynamics). ROD readings were determined using a computer-assisted densitometry program (ImageQuant; Molecular Dynamics). To control for equal loading between samples, the signal of the GR exon $1_{7}$ region was divided by the signal from the $\beta$-actin region amplified from the same sample.

Western blotting. Whole brains were removed from 90 -d-old (adult) male high and low LG-ABN offspring by rapid decapitation $<1$ min after their removal from the home cage. The hippocampi were dissected, snap frozen on dry ice, and stored at $-80^{\circ} \mathrm{C}$. The hippocampal tissue wholecell extract was prepared using tissue sonicated on ice $\left(20 \mathrm{~s}\right.$ pulse at $\left.40^{\circ} \mathrm{C}\right)$ in Tris (20 mm), EDTA (50 mm), and diethyloithiocarbamic acid (0.1 mM; $\mathrm{pH} 8.0$ ) buffer ( $100 \mathrm{ml}$ per $50 \mathrm{~g}$ of hippocampal tissue) containing $\mathrm{NaCl}(0.4 \mathrm{M})$ and protease inhibitors [3.5 $\mathrm{mg}$ of aprotinin, $0.4 \mathrm{mg} / \mathrm{ml}$ 4-(2-aminoethyl) benzenesulfonylfluouride, $1 \mathrm{mg} / \mathrm{ml}$ leupeptin, and 1 $\mathrm{mg} / \mathrm{ml}$ pepstatin]. Aliquots of the supernatant were subsequently taken to determine the levels of protein in the whole hippocampus. Western blots were performed using equal quantities of protein $(40 \mu \mathrm{g})$ separated on Novex 4-12\% Tris-glycine PAGE precast gels (Helixx Technologies, Toronto, Ontario, Canada) with stained molecular markers (SeeBlue; Invitrogen, Burlington, Ontario, Canada) loaded for reference. Proteins were then electrophoretically transferred (Towbin et al., 1979) onto nitrocellulose membranes (Amersham Biosciences). The membranes were blocked $\left(1 \mathrm{~h}, 22^{\circ} \mathrm{C}\right)$ with Carnation dried milk $(5 \%)$ in Tris-buffered saline with Tween-20 (TBS-T) [Tris, $\mathrm{NaCl}$, and Tween-20 (0.1\%), pH 7.6], washed briefly in TBS-T, and incubated $\left(14 \mathrm{~h}, 4^{\circ} \mathrm{C}\right)$ with anti-rat GR- $\alpha$ monoclonal primary antibodies in blocking buffer (1: 4000; Affinity BioReagents, Golden, CO). Membranes were washed with TBS-T (20 min, $\left.22^{\circ} \mathrm{C}\right)$ and then incubated $\left(1 \mathrm{~h}, 22^{\circ} \mathrm{C}\right)$ with horseradish peroxidaseconjugated sheep anti-mouse IgG antibody (1:3000; Amersham Biosciences). After four $15 \mathrm{~min}$ washes with TBS-T, the bands were visualized by enhanced chemiluminescence (Amersham Biosciences) and apposed to autoradiography film (Hyperfilm-MP; Amersham Biosciences) before being developed. A single band was observed at $\sim 92$ $\mathrm{kDa}$. To verify the accuracy of sample loading, selected blots were incubated $\left(70^{\circ} \mathrm{C}, 30 \mathrm{~min}\right)$ in stripping solution $(62.5 \mathrm{~mm}$ Tris- $\mathrm{HCl}, 100 \mathrm{~mm}$ $\beta$-mercaptoethanol, and 2\% SDS) before being blocked $\left(14 \mathrm{~h}, 4^{\circ} \mathrm{C}\right)$ and reprobed $\left(1 \mathrm{~h}, 22^{\circ} \mathrm{C}\right)$ with an $\alpha$-tubulin monoclonal antibody (1: 5000; Biodesign International, Kennebunk, ME). A single band was observed at $\sim 60 \mathrm{kDa}$, and the intensity of the signal were similar in all lanes. ROD readings for the GR- $\alpha$ band was determined using a computer-assisted densitometry program (MCID 4.0; Imaging Research) from samples run in triplicate on three different blots. For all studies, single blots were derived from samples from one animal.

HPA response to restraint stress. HPA stress response testing involved placing 90-d-old (adult) male high and low LG-ABN offspring into Plexiglas restrainers $(8.5 \times 21.5 \mathrm{~cm}$; Kent Scientific, Litchfield, CT) for a 20 min period. Prestress blood samples were taken from rats within $30 \mathrm{~s}$ of removal from the cage, and restraint stress was performed during the light cycle between 12:00 P.M. and 3:00 P.M. with blood sampling (300 $\mu \mathrm{l})$ from the tail vein at 10,20,40,60, and $90 \mathrm{~min}$ after the onset of restraint (Meaney et al., 1989). Plasma (10 $\mu$ l) corticosterone was measured by radioimmunoassay with a highly specific B antiserum (B3-163; Endocrine Sciences, Tarzana, CA) and $\left[{ }^{3} \mathrm{H}\right]$ corticosterone $(101 \mathrm{Ci} /$ mmol; NEN, Boston, MA) tracer. The antiserum cross-reacts slightly with deoxycorticosterone $(\sim 4 \%)$ but not with aldosterone, cortisol, and progesterone $(<1 \%)$. The intraassay and interassay coefficients of variation were 8.8 and $10.4 \%$, respectively. The standard curve $50 \%$ effective concentration was $16 \mu \mathrm{g} / \mathrm{dl}$, and the detection limit of the assay was 0.63 $\mu \mathrm{g} / \mathrm{dl}$.

Forced-swim test. Behavioral stress response testing was performed, as described previously (Porsolt et al., 1977), using 90-d-old (adult) male high and low LG-ABN offspring. Naive animals were placed in a Plexiglas cylinder $(46 \mathrm{~cm}$ high $\times 20 \mathrm{~cm}$ diameter $)$ filled with water $\left(25 \pm 1^{\circ} \mathrm{C}\right)$ to a depth of $30 \mathrm{~cm}$ for $15 \mathrm{~min}$. After the $15 \mathrm{~min}$ training session, the animals were removed from the water and allowed to dry $\left(15 \mathrm{~min}, 32^{\circ} \mathrm{C}\right)$ before being returned to their home cages. After $24 \mathrm{~h}$, the animals were replaced in the water-filled cylinder, and the total duration of immobility was recorded during a $5 \mathrm{~min}$ test session. Immobile behavior was scored whenever the animal remained passively afloat without struggling, in a slightly hunched but upright position with the head slightly immersed (i.e., the rat makes only those movements necessary to keep its head above the water). An observer blind to the experimental conditions scored the behavior. The single $15 \mathrm{~min}$ training exposure was sufficient to produce a relatively constant level of immobility in the subsequent $5 \mathrm{~min}$ test, which was highly reproducible between different groups. 
a

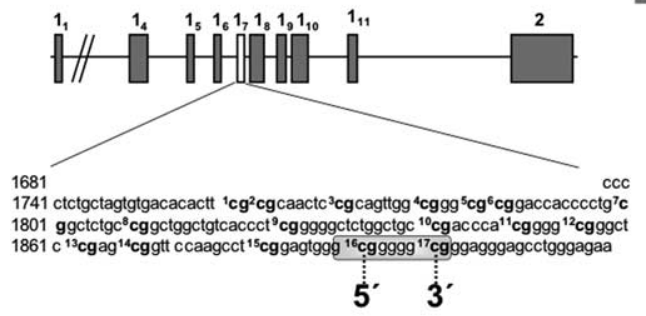

b

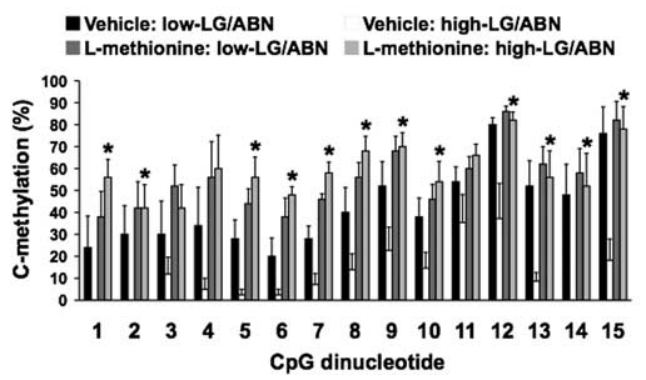

C

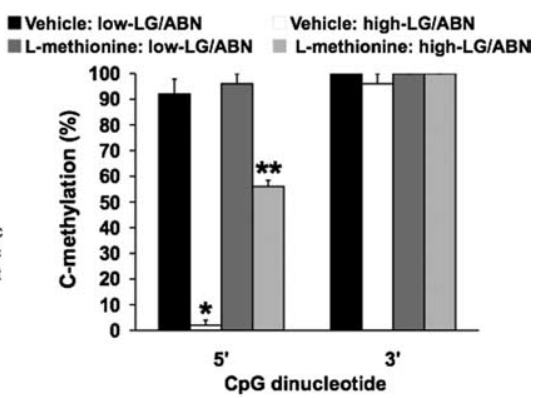

d

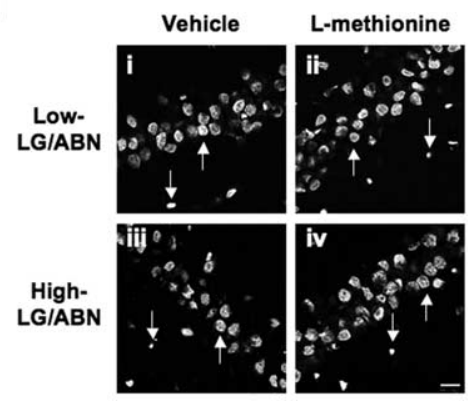

Figure 1. Methionine alters cytosine methylation of GR promoter. $\boldsymbol{a}$, Sequence map of the exon $1_{7}$ GR promoter including the 17 CpG dinucleotides (bold) and the NGFI-A consensus sequence (McCormick et al., 2000) (encircled). b, c, Methylation analysis of the $17 \mathrm{CpG}$ dinucleotides of the exon $1_{7} \mathrm{GR}$ promoter region from vehicle- and methionine-treated ( $\left.100 \mu \mathrm{g} / \mathrm{ml}\right)$ adult high and low LG-ABN offspring ( $6-10$ clones sequenced per animal; $n=4$ animals per group; $\left.{ }^{*} p<0.01\right)$. $\boldsymbol{b}$, Percentage of methylated cytosine residues (mean $\pm S E M$ ) for the first 15 CpG dinucleotides $\left({ }^{*} p<0.05\right)$. c, Percentage of methylated cytosine residues (mean \pm SEM) for the $5^{\prime}$ (site 16) and $3^{\prime}$ (site 17) CpG dinucleotides within the NGFI-A consensus sequence $\left({ }^{*} p<0.0001\right.$; ${ }^{* *} p<$ 0.001). di-div, Confocal photomicrographs of representative 5-mC-positive neurons located within the CA1 hippocampal region of Ammon's horn from vehicle- and methionine-treated ( $100 \mu \mathrm{g} / \mathrm{ml}$ ) adult high and low LG-ABN offspring ( $n=6$ animals per group with 9 sections per animal). Only large round nuclei corresponding to neuronal nuclei (indicated by arrows pointing upward) were included for analysis, and partial or smaller nuclei (indicated by arrows pointing downward) were not included in the quantification. Scale bar, $50 \mu \mathrm{m}$.

\section{Results}

The effects of methionine on the methylation pattern of the exon $1_{7}$ promoter

To determine the effects of methionine treatment, adult offspring of high and low LG-ABN mothers were infused with methionine $(100 \mu \mathrm{g} / \mathrm{ml})$ or saline vehicle once a day for 7 consecutive days, and differences in methylation were mapped using the sodium bisulfite technique (Comb and Goodman, 1990; Clark et al., 1994), with particular interest in the NGFI-A consensus sequence (Fig. 1a). Statistical analysis of the data across all $17 \mathrm{CpG}$ sites (Fig. 1b,c) revealed a significant effect of group $\left(F_{(1,272)}=93.2\right.$; $p<0.0001)$, treatment $\left(F_{(1,272)}=52.8 ; p<0.0001\right)$, and region $\left(F_{(16,272)}=30.4 ; p<0.0001\right)$, as well as a significant group $\times$ treatment $\times$ region interaction $\left(F_{(16,272)}=2.1 ; p=0.0\right)$, group $\times$ treatment interaction $\left(F_{(1,272)}=19.9 ; p<0.0001\right)$, group $\times$ region interaction $\left(F_{(16,272)}=4.1 ; p<0.0001\right)$, and treatment $\times$ region interaction $\left(F_{(16,272)}=2.8 ; p<0.0001\right)$. The results revealed significant differences in the methylation of a number of regions of the exon $1_{7}$ GR promoter sequence (Fig. $1 b$ ) with significant differences within the 5' CpG (site 16) and 3' CpG (site 17) dinucleotides of the NGFI-A consensus sequence (Fig. 1c). As reported previously (Weaver et al., 2004b), the cytosine within the 5' CpG (site 16) dinucleotide is heavily methylated in the offspring of low LG-ABN mothers and rarely in the offspring of high LG-ABN mothers. In contrast, the cytosine within the 3' CpG (site 17) dinucleotide of the NGFI-A consensus sequence is almost always methylated, independent of maternal care. Statistical analysis of the data from these two sites revealed a highly significant effect of group $\left(F_{(1,32)}=54.2\right.$; $p<0.0001)$, treatment $\left(F_{(1,32)}=74.3 ; p<\right.$ $0.0001)$, and region $\left(F_{(1,32)}=115.3 ; p<\right.$ $0.0001)$, as well as a significant group $\times$ treatment interaction $\left(F_{(1,32)}=20.0 ; p<\right.$ $0.0001)$, group $\times$ region interaction $\left(F_{(1,32)}=47.2 ; p<0.000\right)$, and treatment $\times$ region interaction $\left(F_{(1,32)}=4.5\right.$; $p=0.04)$. Post hoc analysis revealed that the cytosine within the 5' CpG dinucleotide of the NGFI-A consensus sequence is significantly $\left({ }^{*} p<0.0001\right)$ hypermethylated in the adult offspring of low LG-ABN mothers compared with the offspring of high LG-ABN dams, and that methionine treatment significantly $\left({ }^{* *} p<0.001\right)$ increased cytosine methylation within the $5^{\prime}$ $\mathrm{CpG}$ dinucleotide in the offspring of high LG-ABN mothers compared with vehicletreated high LG-ABN mothers. Thus, methionine treatment produced "remethylation" of the 5' CpG (site 16) dinucleotide in the offspring of high LG-ABN mothers (Fig. 1c). These findings suggest that methionine treatment can reverse the hypomethylated status of the exon $1_{7}$ GR promoter in the adult offspring of high LG-ABN mothers.

Maternal care altered the methylation status of other $\mathrm{CpG}$ dinucleotides in the exon $1_{7}$ sequence; in the case of sites $1,2,5$, $6,7,8,9,10,12,13,14$, and 15 , the methylation was similarly reversed with central methionine infusion (Fig. $1 b$ ). The significance of these sites for transcription factor binding is currently unknown and a focus of ongoing studies. Thus, stable DNA methylation marked by maternal behavior is reversible in the adult offspring hippocampus by increases in methionine. Methionine altered the methylation of the $5^{\prime} \mathrm{CpG}$ (site 16) dinucleotide within the NGFI-A consensus sequence that is critical for the effect on NGFI-A binding to the exon $1_{7}$ promoter. In a previous in vitro study using electrophilic mobility shift assays with purified recombinant NGFI-A protein (Milbrandt, 1987) and differentially methylated oligonucleotide sequences containing the NGFI-A consensus sequence, we found that methylation of the cytosine within the $5^{\prime} \mathrm{CpG}$ (site 16) dinucleotide completely eliminated the binding of NGFI-A. However, methylation of the cytosine within the $3^{\prime} \mathrm{CpG}$ (site 17) dinucleotide only slightly reduced NGFI-A protein binding (Weaver et al., 2004a).

An important question here is whether the effects of methionine are limited to a subset of genes such as GR or whether they disrupted the DNA methylation patterns across the entire genome. Surprisingly, results from Affymetrix (Santa Clara, CA) microarray analysis performed on hippocampal tissue from a separate cohort of methionine-treated high and low LG-ABN offspring showed that the methionine treatment significantly effected only $\sim 300$ genes, representing $<1 \%$ of the population of genes on the chip (I. C. G. Weaver, M. J. Meaney, and M. Szyf, unpublished observation). These findings suggest an impressive level of specificity. Although we certainly cannot exclude the possibility that some component(s) of the modified genes are relevant for the effects observed here, it would appear that these 
results do not emerge as a function of a widespread alteration in hippocampal gene expression. To further examine whether maternal care or methionine treatment effected global DNA methylation levels, dorsal hippocampal coronal sections from the methionine- or vehicle-treated adult offspring were coimmunostained using antibodies specific for $5-\mathrm{mC}$ or $\mathrm{NeuN}$ to assess genomic methylation levels. The tissue sections were analyzed thoroughly over the entire area of the dentate gyrus and CA1, CA2, and CA3 hippocampal regions of Ammon's horn. However, the staining intensity within the different regions remained the same, regardless of maternal care or methionine treatment. A representative image of $5-\mathrm{mC}$ staining within the CA1 region from each treatment group is shown in Figure $1 d i-d i v$. Neuronal nuclei were only considered positive for 5-mC if they were round and intensely fluorescent in strong contrast to the surrounding tissue. 5-mC labeling intensity and background were consistent among slides. ANOVA revealed no significant effect of group (vehicle-treated high LG-ABN vs vehicle-treated low LG-ABN, $F_{(1,16)}=0.53, p>0.05$ ) or treatment (vehicle-treated low LG$\mathrm{ABN}$ vs methionine-treated low LG-ABN, $F_{(1,16)}=0.42, p>$ 0.05 ; vehicle-treated high LG-ABN vs methionine-treated high LG-ABN, $\left.F_{(1,16)}=0.37, p>0.05\right)$. These results show that neither maternal care nor methionine treatment affected global DNA methylation levels. Our findings suggest that alterations of cytosine methylation in the adult brain through global procedures are surprisingly specific. Methionine alone does not methylate DNA but is converted to the methyl donor SAM in the DNA methylation reaction. An increase in SAM would change the DNA methylation pattern of a gene only if the DNA machinery was present on the gene. Because the DNA is not replicating, it is not expected that maintenance DNA methyltransferases (DNMTs), which are normally present in the replication fork, would be ubiquitously present. It is becoming clear now that chromatin and DNA methylation enzymes are targeted to specific genes in a regulated process. Thus, the specificity of the effect of methionine is likely determined by the occupancy of distinct promoters by DNMTs. It is tempting to speculate that genes involved in crucial regulatory functions, such as GR, are persistently associated with the DNA methylation machinery and are thus hypersensitive to global changes in methionine levels. Future experiments will elucidate the mechanisms, which target the DNA methylation/demethylation machinery to specific genes such as GR in the hippocampus.

\section{The effects of methionine on binding of NGFI-A to the exon $\mathbf{1}_{7}$ promoter}

Differences in methylation of the exon $1_{7}$ GR promoter are tightly associated with effects on histone acetylation and NGFI-A binding (Weaver et al., 2004b). We tested the hypothesis that the effect of methionine on DNA methylation results in (1) decreased histone acetylation at the $\mathrm{K} 9$ residue of the $\mathrm{H} 3$ histone(s) associated with the exon $1_{7}$ GR promoter, (2) decreased interaction between NGFI-A and the promoter sequence, or (3) changes in both histone acetylation and NGFI-A association with the GR promoter. We performed a ChIP analysis of histone $\mathrm{H} 3-\mathrm{K} 9$ acetylation and NGFI-A protein binding to the exon $1_{7}$ GR promoter in the native chromatin environment in vivo. Intact hippocampi from vehicle or methionine $(100 \mu \mathrm{g} / \mathrm{ml})$ treated offspring of high and low LG-ABN mothers were cross-linked in vivo with paraformaldehyde perfusion. We then selectively immunoprecipitated protein-DNA complexes with an antibody against either acetylated histone H3-K9 or NGFI-A. The protein-DNA complexes were uncross-linked, and the precipitated genomic DNA was sub- (a)

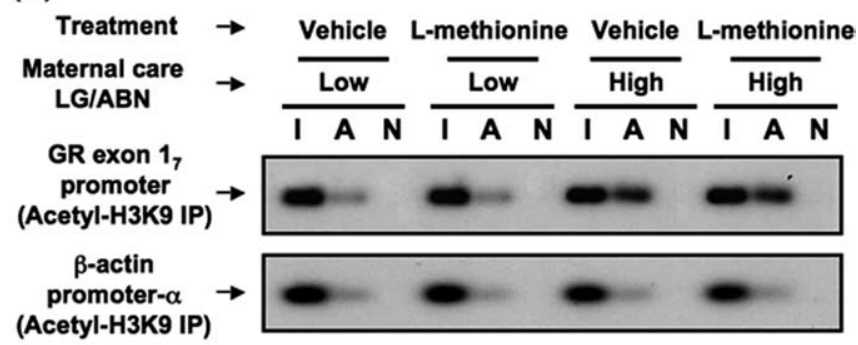

(b)

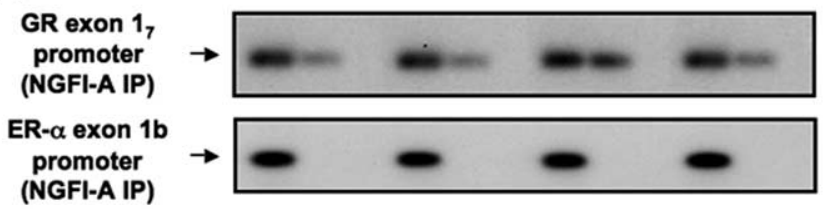

(c)

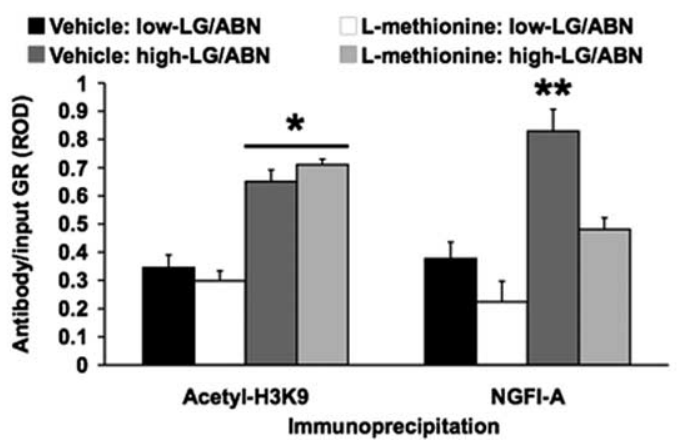

Figure 2. Methionine eliminates maternal effect on NGFI-A binding independently of his tone acetylation. Chromatin immunoprecipitation analysis of the association between histone $\mathrm{H} 3-\mathrm{K} 9$ acetylation and NGFI-A binding to the exon $1_{7}$ GR promoter sequence in hippocampal tissue from vehicle- and methionine-treated ( $100 \mu \mathrm{g} / \mathrm{ml}$ ) adult offspring of high and low LG$\mathrm{ABN}$ mothers ( $n=4$ animals per group). $\boldsymbol{a}, \boldsymbol{b}$, Lanes were loaded with non-immunoprecipitated input (I), acetylated histone $\mathrm{H3}-\mathrm{K} 9$ (top) or NGFI-A (middle) primary antibody immunoprecipitated (A), or non-immune IgG antibody immunoprecipitated (N) hippocampal extracts. $\boldsymbol{a}$, Representative Southern blot of the amplified exon $1_{7}$ region from acetyl-histone $\mathrm{H} 3-\mathrm{K} 9$ immunoprecipitated hippocampal tissue (194 bp band). DNA loading was controlled using primers specific for the ubiquitously expressed $\beta$-actin promoter- $\alpha$ region (171 bp band). $\boldsymbol{b}$, Representative Southern blot of the amplified exon $1_{7}$ region of the GR from NGFI-A immunoprecipitated hippocampal tissue (194 bp band). Exon 1b ER- $\alpha$ promoter region, which does not contain NGFI-A recognition elements (493 bp), amplified from the same NGFI-A immunoprecipitated hippocampal tissue was run as a control for specificity and showed no signal. C, ROD (mean \pm SEM) of exon $1_{7}$ sequence amplified from acetyl-histone H3-K9 or NGFI-A immunoprecipitated hippocampal tissue from vehicle- and methionine-treated $(100 \mu \mathrm{g} / \mathrm{ml})$ adult high and low LG-ABN offspring ( $n=4$ animals per group; ${ }^{*} p<0.01$; ${ }^{* *} p<0.001$ ).

jected to PCR amplification with primers specific for the exon $1_{7}$ GR promoter sequence (Fig. $2 a-c$ ). ANOVA revealed a significant group effect $\left(F_{(1,16)}=10.0 ; p=0.01\right)$ but no significant group $\times$ treatment interaction effect for histone $\mathrm{H} 3-\mathrm{K} 9$ acetylation $\left(F_{(1,16)}=0.8 ; p>0.0\right)$. However, there was a significant group $\times$ treatment interaction effect for NGFI-A $\left(F_{(1,16)}=7.9\right.$; $p=0.01)$. Post hoc analysis showed that vehicle- and methioninetreated offspring of high LG-ABN mothers showed significantly $\left({ }^{*} p<0.01\right)$ greater $\mathrm{H} 3-\mathrm{K} 9$ association with the exon $1_{7}$ sequence than any other group (Fig. $2 a, c$ ), suggesting no effect of methionine treatment on $\mathrm{H} 3-\mathrm{K} 9$ acetylation. In contrast, vehicle-treated offspring of high LG-ABN mothers showed significantly $\left({ }^{* *} p<\right.$ $0.001)$ greater NGFI-A association with the exon $1_{7}$ sequence than any other group (Fig. 2b,c). These results indicate decreased binding of NGFI-A protein to the hippocampal exon $1_{7}$ GR promoter in the adult offspring of methionine-treated high LG-ABN 
mothers compared with the vehicle-treated offspring of high LGABN mothers (Fig. 2b,c); there were no significant differences between methionine-treated offspring of high LG-ABN mothers and either vehicle- or methionine-treated offspring of low LG$\mathrm{ABN}$ dams. The absence of any methionine effect on the offspring of low LG-ABN mothers was expected because, in these animals, the exon $1_{7}$ GR promoter region shows little NGFI-A binding. In summary, methionine treatment decreased binding of NGFI-A to the hippocampal exon $1_{7}$ GR promoter but did not affect levels of histone acetylation. DNA methylation is known to silence gene expression through two different mechanisms. The first is sitespecific DNA methylation, such as methylation of the $5^{\prime} \mathrm{CpG}$ dinucleotide within the NGFI-A binding site, which directly blocks binding of the transcription factor to its cognate sequence and thus inhibits transcription without necessarily altering chromatin structure. The second mechanism is indirect. Methylated DNA binding proteins, such as methyl-CpG binding protein-2 (MeCP-2), are recruited to a region of dense methylation and target HDACs to the chromatin, resulting in histone deacetylation and subsequent chromatin inactivation (Jones et al., 1998; Nan et al., 1998). Although we cannot preclude the involvement of other acetylation sites within histone $\mathrm{H} 3$ or the involvement of acetylation sites within other histones (e.g., histone H4), our data are consistent with the hypothesis that the methionine-induced remethylation of the NGFI-A binding site inhibits transcription by the direct mechanism through blocking NGFI-A binding without altering histone acetylation. This mechanism is also consistent with previous data that revealed an absence of MeCP-2 binding within the hypermethylated GR exon $1_{7}$ promoter region of the adult low LG-ABN offspring (I. C. G. Weaver, M. J. Meaney, and M. Szyf, unpublished observation). Thus, methylation in this case does not result in recruitment of methylated DNA binding proteins and histone deacetylation. We showed previously that, although site-specific methylation is sufficient to block NGFI-A binding to the GR exon $1_{7}$ promoter later in adulthood (as shown here), the GR promoter is both methylated and associated with deacetylated histones at postnatal day 1 (Weaver et al., 2004b). We propose that induction of histone acetylation between postnatal days 1 and 6 enables demethylation of the 5' CpG dinucleotide and binding of NGFI-A, resulting in transcription activation. Thus, there is a unidirectional causal relationship between the state of histone acetylation and the state of methylation of GR exon $1_{7}$ promoter, whereby the state of methylation is determined by the state of histone acetylation and either developmental or pharmacological change in histone acetylation results in demethylation, but methylation does not necessarily alter histone acetylation. Thus, the increased methylation of the 5' CpG site on the exon $1_{7}$ promoter with methionine treatment may be sufficient to inhibit NGFI-A binding, even in the absence of changes in histone acetylation, through site-specific exclusion of transcription factor association.

\section{Effects of methionine on GR expression}

The effect of maternal care on HPA responses to stress is associated with differences in hippocampal GR gene expression and glucocorticoid feedback sensitivity (Meaney, 2001). GR gene expression in the hippocampus is increased in the adult offspring of high compared with low LG-ABN mothers (Francis et al., 1999). This difference is mediated by the differential methylation of the 5' CpG dinucleotide (site 16) of the NGFI-A consensus sequence in the exon $1_{7}$ GR promoter and the subsequent alteration of histone acetylation and NGFI-A binding to the exon $1_{7}$ sequence (Weaver et al., 2004b). If the differential epigenetic marking reg- ulates the expression of the exon $1_{7}$ GR promoter in high versus low LG-ABN offspring, then reversal of the epigenetic marking should accompany a decrease in hippocampal GR expression. To examine whether maternal LG-ABN behavior or methionine treatment affected hippocampal exon $1_{7}$ GR mRNA levels, RTPCR analysis was performed using purified hippocampal mRNA from the vehicle- or methionine-treated adult offspring of high and low LG-ABN mothers (Fig. $3 a$ ). As a positive control, hippocampal mRNA from TSA-treated adult offspring of low LG$\mathrm{ABN}$ mothers was also analyzed because this manipulation has been shown previously to increase GR protein expression. ANOVA revealed a significant effect group $\left(F_{(1,16)}=9.0 ; p=\right.$ $0.01)$ and treatment $(F(1,16)=8.0 ; p=0.01)$ and significant group $\times$ treatment interaction $\left(F_{(1,16)}=11.0 ; p>0.05\right)$. Post hoc analysis showed that TSA-treated offspring of low LG-ABN mothers and vehicle-treated offspring of high LG-ABN dams showed significantly ( ${ }^{*} p<0.001$ and ${ }^{* *} p<0.002$, respectively) greater exon $1_{7}$ GR mRNA levels than any other group (Fig. 3b), suggesting that methionine treatment significantly reduces hippocampal exon $1_{7}$ GR mRNA levels in the offspring of high LGABN dams. This is further supported by the results (Fig. $3 c, d$ ) showing that hippocampal GR protein expression was also significantly decreased in methionine-treated offspring of high LG$\mathrm{ABN}$ mothers to levels that were comparable with those of either the vehicle- or methionine-treated offspring of low LG-ABN mothers. ANOVA revealed highly significant main effects of group $\left(F_{(1,16)}=8.2 ; p=0.01\right)$ and treatment $\left(F_{(1,16)}=16.9 ; p<\right.$ $0.0001)$, as well as a significant group $\times$ treatment interaction effect $\left(F_{(1,16)}=4.2 ; p=0.05\right)$. Post hoc analysis indicated that methionine treatment significantly decreased hippocampal GR expression in the offspring of high LG-ABN mothers (vehicletreated high LG-ABN offspring vs methionine-treated high LG$\mathrm{ABN}$ offspring, ${ }^{*} p<0.001$ ), eliminating the difference in hippocampal GR expression between the offspring of low or high LG-ABN mothers (methionine-treated high LG-ABN offspring vs methionine-treated low LG-ABN offspring, $p>0.90)$. Although methionine treatment significantly reduced GR expression in high LG-ABN adult offspring, global abundance of protein in the hippocampus was not apparently decreased, as indicated by the equal $\alpha$-tubulin immunoreactivity (Fig. 3c).

\section{Effects of methionine on HPA responses to stress}

As adults, the offspring of high LG-ABN mothers show increased hippocampal GR expression, enhanced glucocorticoid feedback sensitivity, and more modest HPA responses to stress than the offspring of low LG-ABN mothers (Liu et al., 1997). Given that methionine treatment reversed the group difference in hippocampal GR expression, we examined the adrenocortical responses to stress in a separate cohort of vehicle- and methioninetreated animals (Fig. 3e). Statistical analysis of the plasma corticosterone data revealed significant effects of group $\left(F_{(1,34)}=\right.$ $4.3 ; p=0.05)$, treatment $\left(F_{(1,34)}=5.2 ; p=0.05\right)$, and time $\left(F_{(1,34)}\right.$ $=22.4 ; p<0.0001)$, as well as a significant group $\times$ treatment interaction effect $\left(F_{(1,34)}=7.8 ; p=0.001\right)$. Post hoc analysis revealed that plasma corticosterone responses to restraint stress in the vehicle-treated adult offspring of high LG-ABN mothers were significantly $\left({ }^{*} p<0.01\right)$ lower than those of methionineand vehicle-treated adult offspring of low LG-ABN mothers or methionine-treated offspring of high LG-ABN mothers. The HPA response to stress in the offspring of low LG-ABN mothers was unaffected by methionine treatment. 
The effects of GR on behavioral responses to stress

Rodents forced to swim in a restricted space from which they cannot escape eventually cease apparent attempts to escape and become immobile (Porsolt et al., 1977). Such learned-helplessness-induced immobility is selectively sensitive to antidepressant treatments (Porsolt et al., 1978). Although adrenalectomized rats acquire the immobile response normally, they are unable to retain the response in subsequent testing, and the effects are reversed by glucocorticoid administration (Funder, 1989). Because maternal behavior affects the level of circulating glucocorticoids and hippocampal GR expression in the offspring, we used the forced-swim test as a model to assess the effects of methionine treatment on behavioral responses to stress in the adult offspring of high and low LG-ABN mothers (Fig. 4). Statistical analysis of the length of time the animals spent immobile revealed significant effects of group $\left(F_{(1,34)}=4.3 ; p=0.048\right)$ and treatment $\left(F_{(1,34)}=4.3 ; p=0.046\right)$, as well as a significant group $\times$ treatment interaction $\left(F_{(1,34)}=7.7 ; p=0.009\right)$. Post hoc analysis revealed that methionine treatment significantly increased the length of time the offspring of high LG-ABN mothers spent immobile in the forced-swim test, comparable with the low LG-ABN animals. Thus, the length of time the vehicletreated adult offspring of high LG-ABN mothers spent immobile was significantly $(p<0.01)$ shorter compared with the methionine- and vehicle-treated adult offspring of low LG-ABN mothers or methionine-treated offspring of high LGABN mothers. Forced-swim test performance by the low LG-ABN offspring was unaffected by methionine treatment. In summary, methionine treatment reversed endocrine and behavioral responses to stress in the adult offspring of high LGABN mothers as well as epigenetic programming of the exon $1_{7}$ GR promoter.

\section{Discussion}

These studies reveal that methionine, a well established dietary modulator of macromolecule methylation, reverses both the DNA methylation pattern of GR promoter and stress responses, thus demonstrating a causal relationship between the programming of responses to stress by maternal behavior and the epigenomic status of the adult offspring. The current data demonstrate that, although epigenomic marks involving stable covalent modifications of the DNA triggered by maternal behavior are stable through life, these marks are potentially reversible even in terminally differentiated tissues such as the hippocampus. Methylation patterns are altered

(c)

(e)

(b)
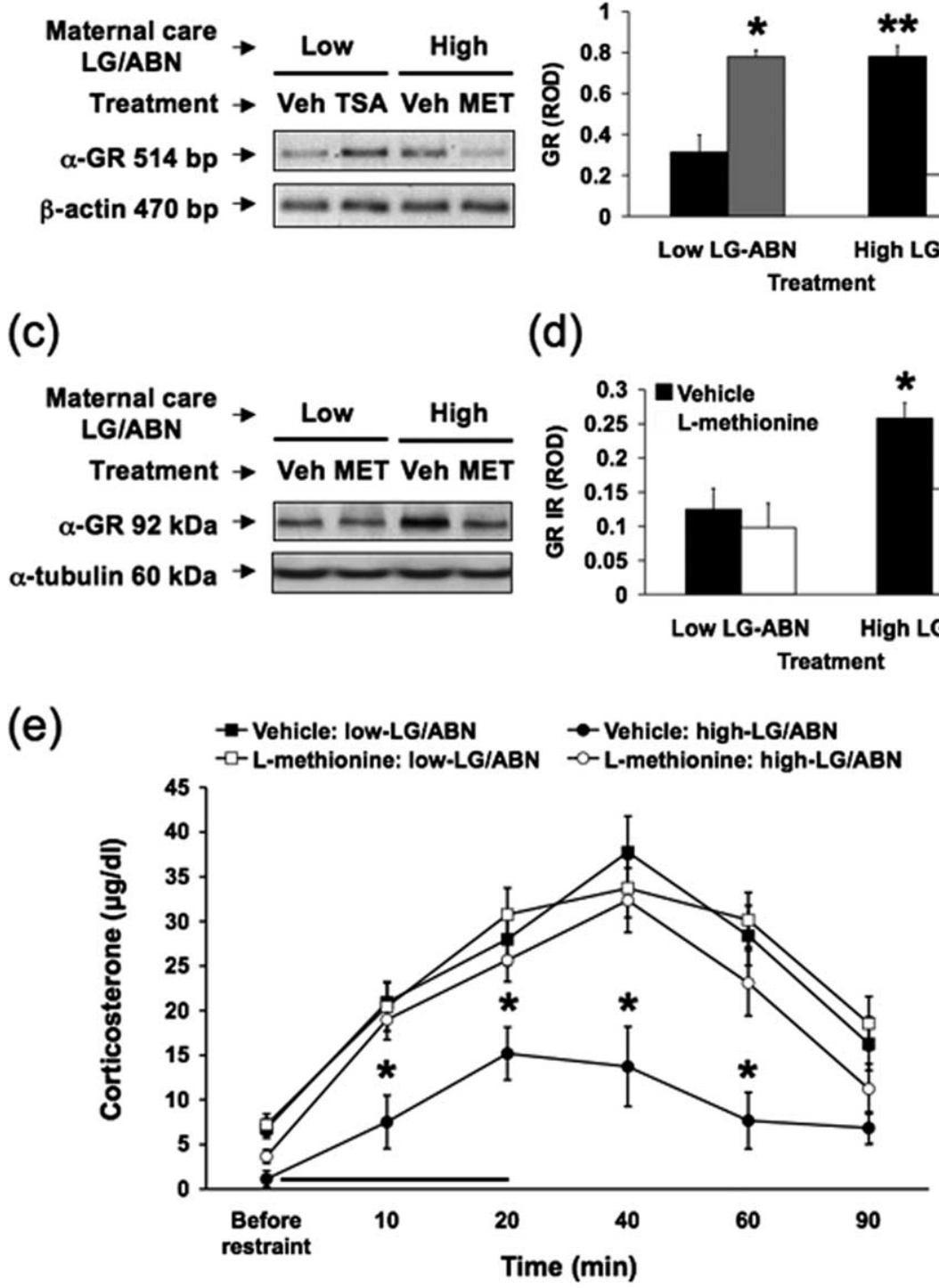

Figure 3. Methionine eliminates the maternal effect on hippocampal GR expression and HPA responses to stress. $\boldsymbol{a}$, Representative RT-PCR illustrating absolute levels of hippocampal GR exon $1_{7}$ mRNA transcript levels from vehicle-treated (Veh), TSAtreated $(100 \mathrm{ng} / \mathrm{ml})$, and methionine-treated (Met) $(100 \mu \mathrm{g} / \mathrm{ml})$ adult offspring of high and low LG-ABN mothers $(n=5$ animals per group). Molecular weight markers (MBI Fermentas Life Sciences) correspond to a single major band at 514 bp. The bottom panel shows the RT-PCR for $\beta$-actin, illustrating absolute hippocampal mRNA transcript levels. Molecular weight markers correspond to a single major band at $470 \mathrm{bp}$, and the intensity of the signal was similar in all lanes. $\boldsymbol{b}$, ROD (mean \pm SEM) of hippocampal GR exon $1_{7}$ mRNA transcript levels from vehicle-, TSA (100 ng/ml)-, and methionine (100 $\left.\mu \mathrm{g} / \mathrm{ml}\right)$-treated adult offspring of high and low LG-ABN mothers ( $n=5$ animals per group; ${ }^{*} p<0.002 ;{ }^{* *} p<0.001$ ). c, Representative Western blot illustrating absolute levels of electrophoresed hippocampal GR immunoreactivity from vehicle- and methionine-treated (100 $\mu \mathrm{g} / \mathrm{ml}$ ) adult offspring of high and low LG-ABN mothers ( $n=5$ animals per group). Molecular weight markers (SeeBlue; Santa Cruz Biotechnology) correspond to a single major band at $92 \mathrm{kDa}$. The bottom panel shows the membrane reprobed for $\alpha$-tubulin immunoreactivity, illustrating absolute levels of electrophoresed hippocampal protein bound to the transfer membrane. Molecular weight markers correspond to a single major band at $\sim 60 \mathrm{kDa}$, and the intensity of the signal was similar in all lanes. $\boldsymbol{d}$, ROD (mean \pm SEM) of hippocampal GR immunoreactivity levels from vehicle- and methionine-treated $(100 \mu \mathrm{g} / \mathrm{ml})$ adult offspring of high and low LG-ABN mothers ( $n=5$ animals per group; $\left.{ }^{*} p<0.001\right)$. e, Mean \pm SEM plasma corticosterone responses to a 20 min period of restraint stress (solid bar) in vehicle- and methionine-treated (100 $\mu \mathrm{g} / \mathrm{ml}$ ) adult offspring of high and low LG-ABN mothers ( $n=10$ animals per group; ${ }^{*} p<0.01$ ). by inhibition of DNMTs or during a change in the supply of methyl donors in cell division during synthesis of the unmethylated nascent strand. However, it is generally believed that methylation patterns remain stable in postmitotic tissues. Our findings provide novel support for a model that suggests a more dynamic 


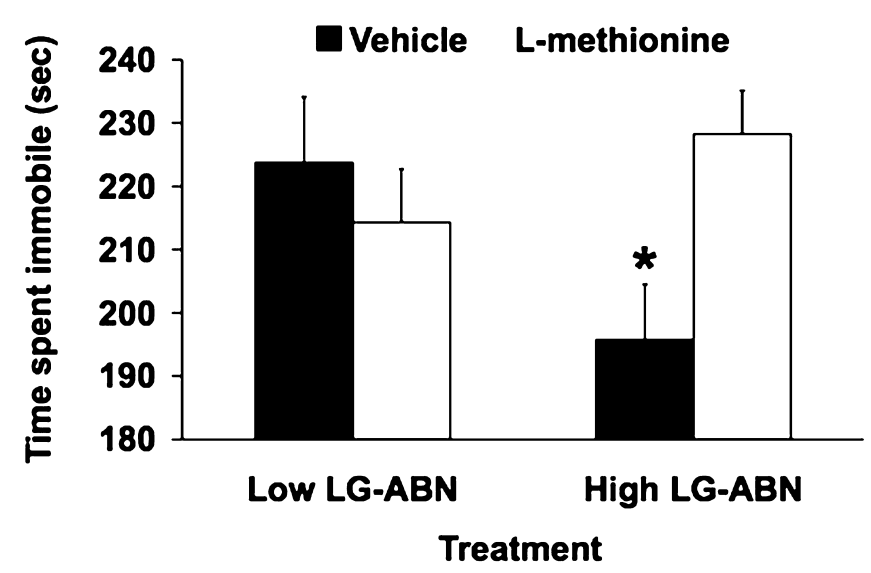

Figure 4. Methionine eliminates the maternal effect on behavioral responses to stress. Mean \pm SEM time spent immobile during a 5 min period of forced-swim stress in vehicle-and methionine-treated $(100 \mu \mathrm{g} / \mathrm{ml})$ adult offspring of high and low LG-ABN mothers ( $n=10$ animals per group; $\left.{ }^{*} p<0.01\right)$.

process in which methylation status is modifiable even in postmitotic cells. These studies, together with our previous paper (Weaver et al., 2004b) showing demethylation after chronic histone deacetylase blockade, demonstrate that the enzymatic machinery necessary for both demethylation and remethylation are operative in differentiated cells such as neurons.

Our previous studies (Weaver et al., 2004b) demonstrate that maternal behavior alters the histone conformation and methylation status of the $5^{\prime} \mathrm{CpG}$ (site 16) dinucleotide within the NGFI-A consensus sequence and the binding of NGFI-A to its cognate sequence in vivo. These data provide an epigenetic mechanism for long-term programming of stress responsivity by experience early in life. Moreover, pharmacological inhibition of histone deacetylation by TSA results in demethylation of the exon $1_{7}$ GR promoter in the adult hippocampus and reversal of the effects of low maternal LG-ABN on stress responsivity (Weaver et al., 2004b). The data presented here show that methionine infusion causes remethylation of the exon $1_{7}$ GR promoter and reversal of high maternal LG-ABN on stress responsivity, by a mechanism independent of histone $\mathrm{H} 3-\mathrm{K} 9$ acetylation. Considering that both TSA and methionine alter DNA methylation indirectly by challenging the accessibility and activity of DNMTs and demethylases, our findings demonstrate that the DNA methylation and demethylation machinery is present in the adult hippocampus and suggest that the balance of these activities plays a pivotal role in the stability of the DNA methylation pattern.

Although the experiments presented here involved infusion of methionine into the left lateral ventricles, they raise the possibility that diet can affect the phenotypes being studied. Because intracellular levels of methionine seem to be affected by both dietary intake and polymorphisms of enzymes involved in methionine metabolism, such as methylenetetrahydrofolate-reductase (Friso et al., 2002), it is tempting to consider, together with our data, the possibility that diet could modify epigenetic programming in the brain not only during early development but also in adult life. Human epidemiological and animal model data indicate that susceptibility to adult-onset chronic disease is influenced by persistent adaptations to prenatal and early postnatal nutrition (Lucas, 1998). Dietary L-methionine is crucial for normal brain development, brain aging, and the pathogenesis of neurodegenerative disorders, playing an essential role in gene expression, protein synthesis, cell signaling, lipid transport/metabolism, and neuron survival (Slyshenkov et al., 2002; Van den
Veyver, 2002). DNA methyltransferase requires SAM to establish or maintain 5-mC patterns. Synthesis of SAM is dependent on the availability of dietary folates, vitamin $\mathrm{B}_{12}$, methionine, choline, and betaine (Cooney, 1993). Maternal methyl supplements affect epigenetic variation and DNA methylation and positively affect health and longevity of the offspring (Wolff et al., 1998; Cooney et al., 2002; Waterland and Jirtle, 2003; Wylie et al., 2003). This could also have important therapeutic implications, because aberrant DNA methylation is involved in neurological disease, such as fragile $\mathrm{X}$ syndrome, and is potentially associated with multiple psychiatric and behavioral conditions, including schizophrenia (Grayson et al., 2005). We hypothesize that reversal of epigenetic states in the brain, such as the remethylation of the exon $1_{7}$ GR promoter illustrated here, could be triggered not only by pharmacological agents but also by stable variations in environmental conditions.

\section{References}

Agrawal AA (2001) Phenotypic plasticity in the interactions and evolution of species. Science 294:321-326.

Caldji C, Tannenbaum B, Sharma S, Francis D, Plotsky PM, Meaney MJ (1998) Maternal care during infancy regulates the development of neural systems mediating the expression of fearfulness in the rat. Proc Natl Acad Sci USA 95:5335-5340.

Cantoni GL (1975) Biological methylation: selected aspects. Annu Rev Biochem 44:435-451.

Champagne FA, Francis DD, Mar A, Meaney MJ (2003) Variations in maternal care in the rat as a mediating influence for the effects of environment on development. Physiol Behav 79:359-371.

Clark SJ, Harrison J, Paul CL, Frommer M (1994) High sensitivity mapping of methylated cytosines. Nucleic Acids Res 22:2990-2997.

Comb M, Goodman HM (1990) CpG methylation inhibits proenkephalin gene expression and binding of the transcription factor AP-2. Nucleic Acids Res 18:3975-3982.

Cooney CA (1993) Are somatic cells inherently deficient in methylation metabolism? A proposed mechanism for DNA methylation loss, senescence and aging. Growth Dev Aging 57:261-273.

Cooney CA, Dave AA, Wolff GL (2002) Maternal methyl supplements in mice affect epigenetic variation and DNA methylation of offspring. J Nutr 132:2393S-2400S.

Crane-Robinson C, Myers FA, Hebbes TR, Clayton AL, Thorne AW (1999) Chromatin immunoprecipitation assays in acetylation mapping of higher eukaryotes. Methods Enzymol 304:533-547.

De Kloet ER, Vreugdenhil E, Oitzl MS, Joels M (1998) Brain corticosteroid receptor balance in health and disease. Endocr Rev 19:269-301.

Detich N, Hamm S, Just G, Knox JD, Szyf M (2003) The methyl donor S-Adenosylmethionine inhibits active demethylation of DNA: a candidate novel mechanism for the pharmacological effects of S-Adenosylmethionine. J Biol Chem 278:20812-20820.

Fleming AS, O'Day DH, Kraemer GW (1999) Neurobiology of motherinfant interactions: experience and central nervous system plasticity across development and generations. Neurosci Biobehav Rev 23:673-685.

Francis D, Diorio J, Liu D, Meaney MJ (1999) Nongenomic transmission across generations of maternal behavior and stress responses in the rat. Science 286:1155-1158.

Friso S, Choi SW, Girelli D, Mason JB, Dolnikowski GG, Bagley PJ, Olivieri O, Jacques PF, Rosenberg IH, Corrocher R, Selhub J (2002) A common mutation in the 5,10-methylenetetrahydrofolate reductase gene affects genomic DNA methylation through an interaction with folate status. Proc Natl Acad Sci USA 99:5606-5611.

Frommer M, McDonald LE, Millar DS, Collis CM, Watt F, Grigg GW, Molloy PL, Paul CL (1992) A genomic sequencing protocol that yields a positive display of 5-methylcytosine residues in individual DNA strands. Proc Natl Acad Sci USA 89:1827-1831.

Funder JW (1989) Hormonal regulation of gene expression. Biochem Soc Symp 55:105-114.

Grayson DR, Jia X, Chen Y, Sharma RP, Mitchell CP, Guidotti A, Costa E (2005) Reelin promoter hypermethylation in schizophrenia. Proc Natl Acad Sci USA 102:9341-9346. 
Higley JD, Hasert MF, Suomi SJ, Linnoila M (1991) Nonhuman primate model of alcohol abuse: effects of early experience, personality, and stress on alcohol consumption. Proc Natl Acad Sci USA 88:7261-7265.

Jones PL, Veenstra GJ, Wade PA, Vermaak D, Kass SU, Landsberger N, Strouboulis J, Wolffe AP (1998) Methylated DNA and MeCP2 recruit histone deacetylase to repress transcription. Nat Genet 19:187-191.

Levine S (1994) The ontogeny of the hypothalamic-pituitary-adrenal axis. The influence of maternal factors. Ann NY Acad Sci 746:275-288; discussion 289-293.

Liu D, Diorio J, Tannenbaum B, Caldji C, Francis D, Freedman A, Sharma S, Pearson D, Plotsky PM, Meaney MJ (1997) Maternal care, hippocampal glucocorticoid receptors, and hypothalamic- pituitary-adrenal responses to stress. Science 277:1659-1662.

Lucas A (1998) Programming by early nutrition: an experimental approach. J Nutr 128:401S-406S.

McCormick JA, Lyons V, Jacobson MD, Noble J, Diorio J, Nyirenda M, Weaver S, Ester W, Yau JL, Meaney MJ, Seckl JR, Chapman KE (2000) 5 '-heterogeneity of glucocorticoid receptor messenger RNA is tissue specific: differential regulation of variant transcripts by early-life events. Mol Endocrinol 14:506-517.

Meaney MJ (2001) Maternal care, gene expression, and the transmission of individual differences in stress reactivity across generations. Annu Rev Neurosci 24:1161-1192.

Meaney MJ, Aitken DH, Viau V, Sharma S, Sarrieau A (1989) Neonatal handling alters adrenocortical negative feedback sensitivity and hippocampal type II glucocorticoid receptor binding in the rat. Neuroendocrinology 50:597-604.

Milbrandt J (1987) A nerve growth factor-induced gene encodes a possible transcriptional regulatory factor. Science 238:797-799.

Mudd SH, Cantoni GL (1958) Activation of methionine for transmethylation. III. The methionine-activating enzyme of Bakers' yeast. J Biol Chem 231:481-492.

Myers MM, Brunelli SA, Shair HN, Squire JM, Hofer MA (1989) Relation- ships between maternal behavior of SHR and WKY dams and adult blood pressures of cross-fostered F1 pups. Dev Psychobiol 22:55-67.

Nan X, Ng HH, Johnson CA, Laherty CD, Turner BM, Eisenman RN, Bird A (1998) Transcriptional repression by the methyl-CpG-binding protein MeCP2 involves a histone deacetylase complex. Nature 393:386-389.

Porsolt RD, Le Pichon M, Jalfre M (1977) Depression: a new animal model sensitive to antidepressant treatments. Nature 266:730-732.

Porsolt RD, Anton G, Blavet N, Jalfre M (1978) Behavioural despair in rats: a new model sensitive to antidepressant treatments. Eur J Pharmacol 47:379-391.

Slyshenkov VS, Shevalye AA, Liopo AV, Wojtczak L (2002) Protective role of L-methionine against free radical damage of rat brain synaptosomes. Acta Biochim Pol 49:907-916.

Towbin H, Staehelin T, Gordon J (1979) Electrophoretic transfer of proteins from polyacrylamide gels to nitrocellulose sheets: procedure and some applications. Proc Natl Acad Sci USA 76:4350-4354.

Van den Veyver IB (2002) Genetic effects of methylation diets. Annu Rev Nutr 22:255-282.

Waterland RA, Jirtle RL (2003) Transposable elements: targets for early nutritional effects on epigenetic gene regulation. Mol Cell Biol 23:5293-5300.

Weaver IC, Diorio J, Seckl JR, Szyf M, Meaney MJ (2004a) Early environmental regulation of hippocampal glucocorticoid receptor gene expression: characterization of intracellular mediators and potential genomic target sites. Ann NY Acad Sci 1024:182-212.

Weaver IC, Cervoni N, Champagne FA, D’Alessio AC, Sharma S, Seckl JR, Dymov S, Szyf M, Meaney MJ (2004b) Epigenetic programming by maternal behavior. Nat Neurosci 7:847-854.

Wolff GL, Kodell RL, Moore SR, Cooney CA (1998) Maternal epigenetics and methyl supplements affect agouti gene expression in Avy/a mice. FASEB J 12:949-957.

Wylie LM, Robertson GW, Hocking PM (2003) Effects of dietary protein concentration and specific amino acids on body weight, body composition and feather growth in young turkeys. Br Poult Sci 44:75-87. 